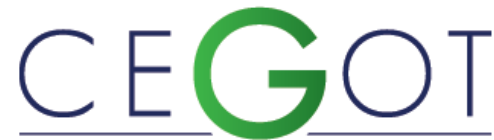

Centro de Estudos de Geografia e Ordenamento do Território
Geografia e Ordenamento do Território, Revista Eletrónica Centro de Estudos de Geografia e Ordenamento do Território http://cegot.org

ROBAINA, LUÍS

Universidade Federal de Santa Maria, Dpto de Geociências

Av. Roraima, 1000, Campus da UFSM, Prédio 17, sala 1113c. CEP:97105-900

- Santa Maria/RS - Brasil

lesrobaina@yahoo.com.br

TRENTIN, ROMARIO

Universidade Federal de Santa Maria, Dpto de Geociências

Av. Roraima, 1000, Campus da UFSM, Prédio 17, sala 1113c. CEP:97105-900

- Santa Maria/RS - Brasil

romario.trentin@gmail.com

\title{
Estudos e zoneamento geoambiental do município de São Francisco de Assis - Oeste do Rio Grande do Sul
}

Studies and geo-environmental zoning on the municipality of São Francisco de Assis - Rio Grande do Sul West

Referência: Robaina, Luís; Trentin, Romario (2019). Estudos e zoneamento geoambiental do município de São Francisco de Assis - Oeste do Rio Grande do Sul. Revista de Geografia e Ordenamento do Território (GOT), n. ${ }^{\circ} 16$ (março). Centro de Estudos de Geografia e Ordenamento do Território, p. 323-344, dx.doi.org/10.17127/got/2019.16.014

\section{RESUMO}

Os estudos Geoambiental representam importante instrumento para o planejamento e análise das formas de uso e ocupação do solo. Este tipo de trabalho quando associado às questões geomorfológicas trazem resultados importantes para os zoneamentos e planejamentos regionais. Desta forma, o presente trabalho teve como objetivo a definição do zoneamento Geoambiental do município de São Francisco de Assis(SFA), localizado no oeste do estado do Rio Grande do Sul, utilizando como parâmetros de análise, as condições de relevo, litologia, solos e uso e ocupação. A metodologia aplicada, segue a proposta de Trentin e Robaina (2005) onde definem que o zoneamento Geoambiental, se refere ao parcelamento de um determinado espaço geográfico e tem seu direcionamento na determinação das fragilidades e potencialidades ambientais das paisagens. Para isso, utilizam-se os parâmetros ambientais do substrato geológico, as formas do relevo, feições da rede hidrográfica, características do solo e feições superficiais. O uso e ocupação da terra, completam os dados para análise e compartimentação geoambiental final. Como resultados finais, foram definidas onze unidades que apresentam um comportamento homogêneo em relação aos processos superficiais, sendo elas: Planalto Leste - Serra dos Canários; Planalto Oeste - Serra dos Canários; Rebordo do Planalto; Colinas Vulcânicas; Colinas Arenosas; Campos de Areia; Silvicultura; Urbano; Cerros de São Francisco; Colinas do Baixas do Rio Jaguari e Vales Fluviais.

Palavras-chave: Análise de Relevo; Formas de uso e ocupação; Litologia; Solos; Zoneamento Geoambiental 


\section{ABSTRACT}

Geoenvironmental studies represent an important instrument for the planning and analysis of land use and occupation forms. This type of work when associated with geomorphological issues brings important results for zoning and regional planning. The objective of this study was to define the Geoenvironmental zoning of the municipality of São Francisco de Assis(SFA), located in the Western part of the Rio Grande do Sul, using as analysis parameters the relief conditions, lithology, soils and occupation. The applied methodology follows the proposal of Trentin and Robaina (2005) where they define that Geoenvironmental Zoning refers to the division of a certain geographic space and has its direction in determining the fragilities and environmental potential of the landscapes. For this, the environmental parameters of the geological substrate, the landforms, features of the hydrographic network, soil characteristics and surface features are used. The use and occupation of the land complete the data for final Geoenvironmental analysis and compartmentalization. As final results, eleven units were defined that present a homogeneous behavior in relation surface processes, being: Plateau Leste - Serra dos Canários; Plateau Oeste - Serra dos Canários; Rim of the Plateau; Volcanic Hills; Sandy Hills; Sand Fields; Forestry; Urban; São Francisco Hills; Lowlands of the Jaguari River and Fluvial valleys.

Keywords: Relief Analysis; Forms of use and occupation; Lithology; Soil; Geoenvironmental Zoning.

\section{Introdução}

O zoneamento e mapeamento geoambiental é um importante instrumento para o planejamento e regulação do uso e ocupação do solo. Este tipo de mapeamento quando associado às questões geomorfológicas trazem resultados mais precisos e satisfatórios para o zoneamento. Dentro desta ótica Grecchi e Pejon (1998) afirmam que os estudos de natureza geoambiental possibilitam a caracterização de áreas quanto às suas aptidões e restrições às atividades já em desenvolvimento e/ou prováveis de serem implantadas, além de indicar porções do terreno com uma maior qualidade ambiental que possam ser preservadas.

Um dos precursores dos trabalhos de cartografia geoambiental foi Cendrero (1975) que realizou no norte da Espanha, um mapeamento geológico-ambiental baseado na metodologia e conceitos utilizados pelo Departamento de Geologia Econômica do Texas.

Autores como Fiori (2004) e Carvalho et al. (2004) indicam que a elaboração do zoneamento geoambiental se baseia na associação de mapas temáticos, entre os quais se destacam o 
Geológico, o Geomorfológico, o Pedológico, o Litológico, o de Declividade, a Drenagem e o Uso e Ocupação do Solo. A síntese dos mapas temáticos e a integração dos parâmetros para a definição adequada dos limites de cada unidade são facilitadas pelas ferramentas de cartografia digital e Sistemas de Informação Geográfica (SIG).

Para Trentin e Robaina (2005), o zoneamento geoambiental tem como proposta fundamental a divisão da área analisada em unidades de acordo com as características de seus atributos. As unidades representam áreas com heterogeneidade mínima quanto aos atributos e com respostas semelhantes frente aos processos de dinâmica superficial. Uma unidade pode ser formada por um único atributo que por si só define as condições específicas do comportamento ambiental ou pode ser formada por uma associação de atributos que juntos definem as particularidades da unidade.

Lang; Blaschke (2009, p. 41) definem que as ferramentas disponibilizadas pelos SIG's permitem sobrepor diferentes atributos, como caracterização do meio físico e ocupação e, com isso, agilizam as análises e promovem conclusões mais precisas. "Além disso, também se observa que o Sistema de banco de dados permite que usuários menos especializados possam realizar as consultas de forma fácil e dinâmica e obtenham os resultados desejados".

Como exemplo da aplicação dos mapeamentos geoambientais, cita-se o trabalho desenvolvido por Souza, et al (2005) o qual utiliza a cartografia geoambiental, como suporte para a elaboração do Plano Diretor Ambiental e Urbanístico da cidade de Mariana, no estado de Minas Gerais. Mapeamento de unidades geoambientais foram desenvolvidas também por Higashi (2004) que apresentou uma caracterização das unidades geoambientais de São Francisco do Sul, no Estado de Santa Catarina.

Em 2007, o trabalho de Diagnóstico Geoambiental da Bacia do Córrego Tenente Mariluz/PR, desenvolvido por Souza, Gasparetto e Nakashima (2008) e o trabalho intitulado Zoneamento geoambiental em áreas rurais. Subsídios ao planejamento de projetos de reforma agrária. Estudo de caso: assentamento rural Pirituba II, (SP), de autoria de Shimbo e Jiménez-Rueda (2007), apresentam como base a relação entre as informações da rede de drenagem, geologia estrutural, fisiográficas e pedológicas, que permitiram estabelecer as zonas geoambientais. Danilo Francisco Trovó Garófalo e Marta Felícia Marujo Ferreira 
(2013) realizaram uma análise geoambiental de bacias hidrográficas situadas em áreas de transição urbano-rural, na bacia do ribeirão do Pântano, Alfenas (MG).

Na área de estudo, o trabalho dos autores De Nardin e Robaina (2009) estabelece o zoneamento geoambiental da bacia hidrográfica do arroio Miracatu, já Trentin (2011), estabeleceu o mapeamento geoambiental da bacia hidrográfica do Rio Itu, porção norte do município de São Francisco de Assis. Além destes, trabalhos científicos de mapeamento temático foram desenvolvidos, também, por Menezes et al. (2013), Robaina et al (2015), Suertegaray et al. (2001), Trentin et al. (2012; 2013, 2015), Trentin e Robaina (2012) e Verdum (2004).

Assim sendo, o presente trabalho apresenta como objetivo a definição do zoneamento Geoambiental do município de São Francisco de Assis, utilizando como parâmetros de análise, as condições de relevo, litologia, solos e uso e ocupação.

\subsection{Localização da área de trabalho}

O município de São Francisco de Assis está localizado na Região Sul do Brasil, na porção Oeste do Estado do Rio Grande do Sul, dentro da Mesorregião Centro-Oriental Riograndense, na Zona Missioneira, distante 485 km da capital gaúcha, Porto Alegre, e a 142 km a oeste de Santa Maria - RS.

A área do município é de $2.501,2 \mathrm{~km}^{2}$, estando limitado geograficamente pelas coordenadas $54^{\circ} 47^{\prime} 02^{\prime \prime}$ a $55^{\circ} 53^{\prime} 54^{\prime \prime}$ de longitude oeste e $29^{\circ} 10^{\prime} 03^{\prime \prime}$ a $29^{\circ} 43^{\prime} 05^{\prime \prime}$ de latitude sul, Figura 1. Em suas divisas municipais, temos os municípios de Maçambara, Unistalda e Santiago ao norte, os municípios de Nova Esperança do Sul e Jaguari a leste, Alegrete e São Vicente do Sul ao sul e Manoel Viana a oeste. 


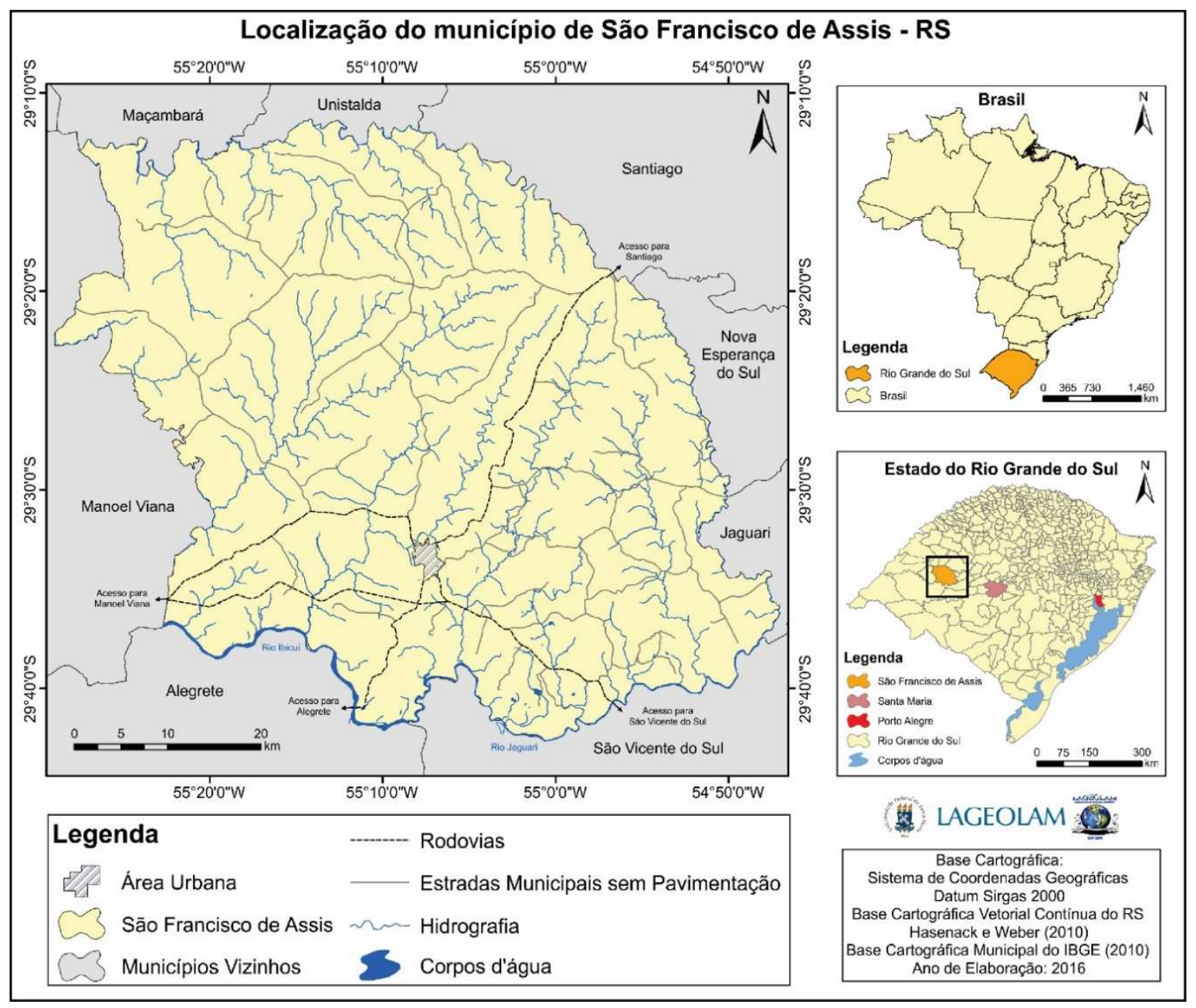

Figura 1 - Localização do município de São Francisco de Assis.

\section{Procedimentos metodológicos}

O termo "zoneamento", na presente proposta, refere-se ao parcelamento de um determinado espaço geográfico e tem seu direcionamento na determinação das fragilidades e potencialidades ambientais das paisagens. Para isso, utilizam-se os parâmetros ambientais do substrato geológico, as formas do relevo, feições da rede hidrográfica, características do solo e feições superficiais. O uso e ocupação da terra completam os dados para análise e compartimentação geoambiental final.

A figura 2 apresenta um fluxograma com os níveis dos documentos utilizados e elaborados na definição do mapa Geoambiental. 


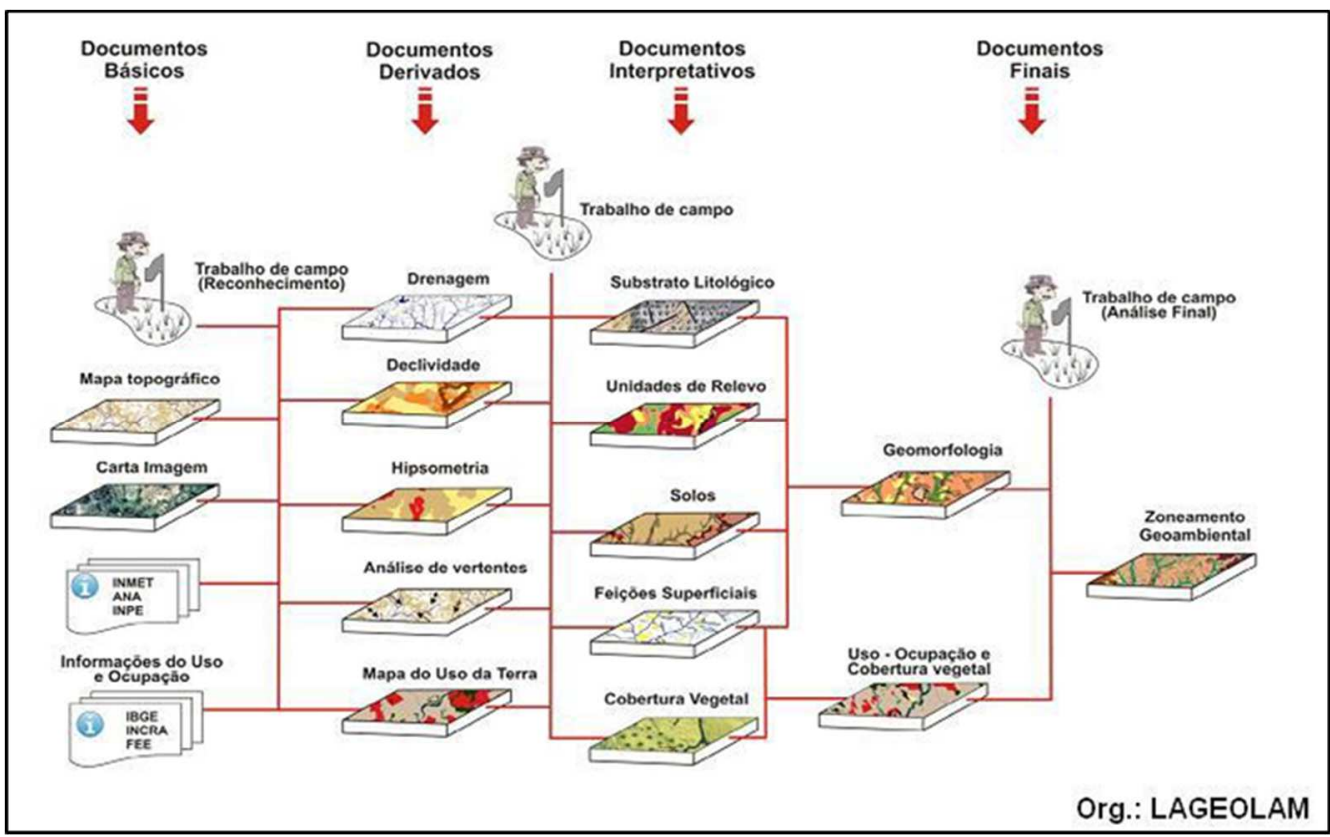

Figura 2 - Fluxograma metodológico de elaboração do zoneamento Geoambiental

Na definição de uma unidade ambiental homogênea pode-se utilizar um único parâmetro ou um grupo deles para formar uma unidade, que é a base para a análise de uma área. Define-se como parâmetro o elemento base que será inserido e manuseado sobre um documento cartográfico, como informação que representa parte dos componentes do ambiente.

Os estudos para elaboração do mapa Geoambiental iniciam com um grupo de documentos básicos. Nesta etapa são obtidos os mapas topográficos, carta imagem e demais mapas préexistentes. As informações de uso e ocupação são obtidas através de pesquisa de dados socioeconômicos do município em órgãos públicos e privados. Nesta etapa os trabalhos de campo são de reconhecimento da área.

Os documentos derivados são produtos da integração de dados e da compilação de mapas básicos. A elaboração de mapas dentro dos estudos geográficos representa importante fase para o entendimento da evolução dos ambientes naturais, relacionados às formas, gênese e processos.

O estudo do relevo parte da análise e cartografia de suas características principais, determinadas pela hipsometria, declividade, amplitude, comprimento, perfil e plano de 
vertente. Nesta etapa de desenvolvimento dos documentos derivados, é elaborado o mapa de uso da terra, com base na carta imagem, que reflete áreas distintas da paisagem em um determinado momento.

Os documentos interpretativos são realizados a partir das informações e dos levantamentos, contidos nos documentos básicos e derivados, apoiados por trabalhos de campo. Os trabalhos de campo são realizados de forma investigativa, através de perfis, com apoio das imagens e cartas topográficas. Os pontos coletados e inseridos em uma base georreferenciada, possibilitam a geração de planos de informação (PIs), onde são construídos os mapas.

A vegetação é determinada a partir da definição do grau de cobertura do solo. Diferencia-se a cobertura vegetal pelo aspecto fisionômico predominante em campestre, arbustiva ou florestal e ocorrência de vegetação original ou exótica.

Os documentos finais são caracterizados pelas modificações antrópicas e por feições que representam a dinâmica envolvida na interação entre a natureza e o homem.

O zoneamento Geoambiental do município de São Francisco de Assis, apoiou-se no uso das geotecnologias e processamentos em SIG, especificamente com as ferramentas de análise estatística e espacial do Arcgis $10.2^{\circledR}$. A definição das unidades Geoambientais ocorreu através das análises e cruzamento das camadas do mapeamento de solos, litologia, unidades morfolitológicas e o mapeamento de uso. A Figura 3 mostra a espacialização das variáveis utilizadas na definição das unidades Geoambientais. 


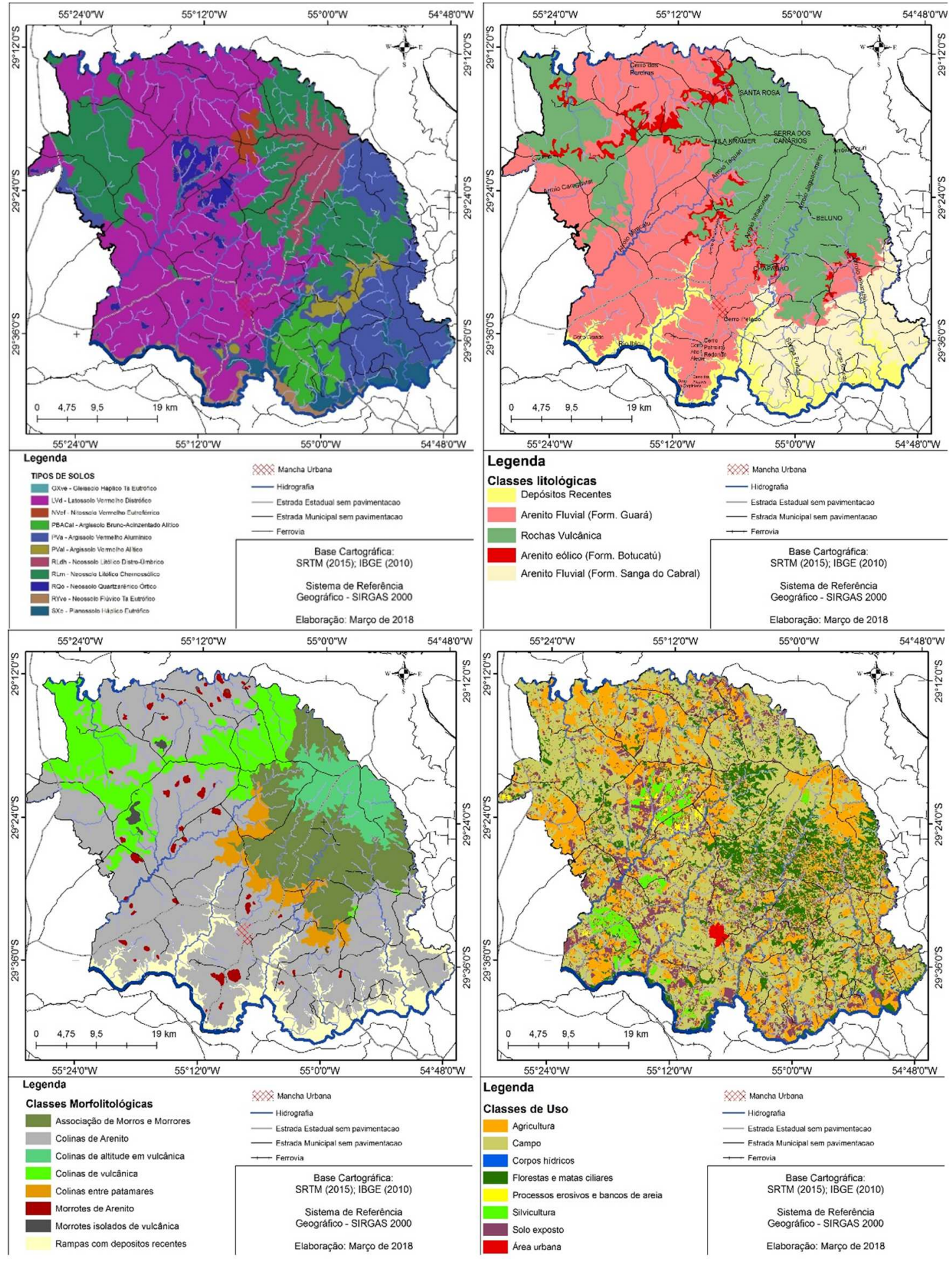

Figura 3 - Mapas base para a definição das unidades Geoambientais do município de São Francisco de Assis. 


\section{Principais características}

No município de São Francisco de Assis o sentido principal dos cursos d'água são de NE-SW, desaguando no Rio Ibicuí e no rio Jaguari que, também, é um afluente do Ibicuí. O arranjo espacial dos cursos fluviais apresenta um padrão predominantemente retangulardendrítico, com um total de $2.891,8 \mathrm{~km}$ de canais.

A amplitude altimétrica é de 380 metros, como a menor altitude na cota de 80 metros, junto às planícies do rio Ibícui, na porção sul do município e a maior altitude se apresenta na cota de 460 metros, na porção Nordeste do município. De forma geral, o município de SFA apresenta um relevo ondulado, onde predominam declividades entre 5 a $15 \%$.

Conforme Robaina et al. (2010), este município está localizado sobre duas grandes unidades geomorfológicas do Rio Grande do Sul que são: Depressão Central e o Planalto da Serra Geral. Na unidade da Depressão Central forma o relevo denominado Modelados dos Patamares residuais em arenitos, que se caracteriza por um relevo ondulado em rochas friáveis e áreas planas aluviais. Na unidade do Planalto da Serra geral, forma o relevo dos Modelados de Patamares das Missões e dos Modelados de Rebordo do Planalto.

As rochas que afloram no município estão associadas a uma sequência vulcano-sedimentar, depositados na Bacia Sedimentar do Paraná. As rochas mais antigas que afloram no município correspondem a uma espessa sucessão flúvio-eólica representada por arenitos com presença comum de micas e por apresentar concreções carbonáticas, pertencente a Formação Sanga do Cabral (Lavina,1988). A sequência sobrejacente corresponde a um substrato identificado por uma sequência de arenitos com grânulos e associações com sequência pelíticas de características fluviais que conforme Wildner et al. (2006) constituem a Formação Guará. Em algumas porções a alta coesão dos grãos, devido à intensa concentração de óxido de ferro e, por vezes, sílica, confere às rochas maior resistência, geralmente nas camadas superiores, expondo feições de relevo com encostas íngremes e afloramentos de rochas. Por outro lado, estas rochas apresentam-se muito friáveis e com alto grau de alteração, quando pouco cimentadas, o que condiciona a formação de intensos processos erosivos.

No final do Jurássico, início do Cretáceo com avanço do Deserto na Bacia do Paraná os sedimentos estão representados por uma sequência eólica da Formação Botucatú, 
compostas por arenito avermelhado, finos a médios, bem selecionados com grãos arredondados e com alta esferecidade. A fragmentação do grande continente da Pangea gerou pacotes de lavas da Formação Serra Geral de composição básica e ácida, constituindo um empilhamento de lavas. Nos intervalos entre os sucessivos pacotes de lavas ocorre, eventualmente, a deposição de sedimentos arenosos, constituindo os arenitos intertrápicos. As sequências geológicas mais recentes ocorrem nas áreas de acumulação, junto à planície de inundação, na calha dos arroios e ao longo de sua planície de inundação.

Com base na EMPRAPA, (1999), no município de São Francisco de Assis encontram-se as seguintes classes de solos (conforme o Sistema Brasileiro de Classificação de Solos - SiBCS de 1999): solos hidromórficos divididos em Gleissolos, Planossolos e Neossolos quartzarênicos flúvicos; solos mal desenvolvidos dos tipos Cambissolos e Neossolos litolicos e quartzarênicos; e os solos bem desenvolvidos que são definidos como Argissolos, Latossolos e Nitossolos.

Os solos hidromórficos estão associados, principalmente, às várzeas dos grandes rios que marcam divisas do município como o rio Jaguari e o rio Ibicuí. Sobre o substrato de rochas vulcânicas com relevo ondulado são comuns solos mal desenvolvidos formando uma associação de Cambissolos e Neossolos litólicos, que muitas vezes apresentam o Horizonte pedológico A com matéria orgânica e pedregoso, constituindo horizonte chernossólico.

$\mathrm{Na}$ porção NE do município, ainda com substrato vulcânico, ocorrem solos bem desenvolvidos que são classificados como Argissolos Vermelhos e estão associados a porções menos resistentes dos derrames. Estes solos, também, ocorrem na porção SE do município, sobre um substrato de arenitos finos em relevo de colinas. Nas porções mais finas, menos permeáveis dos arenitos, ocorrem Argissolos Bruno, enquanto, nas porções mais arenosas Argissolos Vermelhos. Junto a Vila Kramer com uma alteração mais importante, devido a ocorrência da porção de topo de derrame, desenvolvem-se porções com solos minerais homogêneos, com estrutura do horizonte subsuperficial de blocos ou prismas bem definidos, com cerosidade, classificados como Nitossolos vermelhos.

Associados aos arenitos médios a finos das Formações Guará e Botucatu, que predominam no município, desenvolvem-se solos classificados como Latossolos vermelhos com textura arenosa e algumas vezes Neossolos Quartzarênicos devido à rocha original possuir pouca 
argila e poucos minerais alteráveis. Os Neossolos ocorrem em um relevo ondulado com vegetação xerófila identificada como butiazeiro-anão (Butia lallemantii) que se caracteriza por uma palmeira anã e cespitosa, com copa hemisférica, de $70-120 \mathrm{~cm}$ de altura que podem formar grandes áreas. A degradação destes solos gera campos de areia, muito comuns na porção central do município, onde a ação do vento desenvolve dunas.

\subsection{Uso e ocupação}

A área urbana caracterizada pelo adensamento residencial, ocorrência de áreas com comércios e centros administrativos, está localizada na porção centro sul com abrangência de cerca de $0,2 \%$ de sua área territorial.

As lavouras se caracterizam por locais onde são realizados os cultivos agrícolas com predomínio de monoculturas temporárias como a soja, cana-de-açúcar, mandioca, milho e arroz (IBGE, 2014). No município também são observadas grandes áreas com cultivos de trigo. Se localizam principalmente nas porções norte, leste e oeste do município com abrangência de cerca de $22,6 \%$ de sua área territorial.

Os campos e pastagens são caracterizados pelo predomínio de grandes áreas com gramíneas plantadas e nativas, que são utilizadas para pecuária onde ocorrem a criação extensiva de gado bovino e ovino. Encontram-se distribuídos principalmente nas porções nordeste, noroeste e centro-sul do município com abrangência de cerca de $46,5 \%$ de sua área territorial.

Associado às áreas de lavouras, ocorrem os solos expostos que são áreas onde os solos ficam expostos pelo período de entressafras, podendo ocorrer o desenvolvimento de processos erosivos. Os locais com solo exposto encontram-se principalmente nos setores nordeste, centro e sudoeste do município com abrangência de cerca de $13,7 \%$ da área territorial.

As matas de encostas e ciliares são caracterizadas principalmente pela presença de concentrações de espécies vegetais nativas de porte arbóreo-arbustivo. A silvicultura é caracterizada por grandes extensões de áreas plantadas, ou seja, locais utilizados para o cultivo de espécies vegetais arbóreas exóticas, principalmente eucalipto (Eucalyptus sp.). 
Nas planícies de inundação dos canais principais dos rios Ibicuí e Jaguari e seus afluentes ocorre atividade agrícola, com orizicultura. O rio Ibicuí, para o município, também tem importância ao uso como Balneário, na Praia do Jacaquá.

\section{Zoneamento geoambiental}

O zoneamento geoambiental pode ser considerado uma técnica de integração e síntese de informações temáticas que identificam padrões de vulnerabilidade e potencialidade diferenciados.

O mapa da figura 4 mostra a distribuição espacial das unidades geoambientais do município de São Francisco de Assis e, a tabela 1, apresenta os dados quantitativos das áreas e percentagens das unidades. Para o referido município foram definidas 11 unidades geoambientais, as quais apresentam características homogêneas quanto às condições topográficas de substrato geológico, solos e formas de uso.

\begin{tabular}{|l|c|c|}
\hline \multicolumn{1}{|c|}{ Unidades Geoambientais } & Área km² & Percentagem \\
\hline 1 - Unidade Planalto Leste - Serra dos Canários & 75,57 & 3,01 \\
\hline 2 - Unidade Planalto Oeste - Serra dos Canários & 67,58 & 2,69 \\
\hline 3 - Unidade Rebordo do Planalto & 460,59 & 18,36 \\
\hline 4 - Unidade de Colinas Vulcânicas & 418,75 & 16,69 \\
\hline 5 - Unidade Colinas Arenosas & 774,13 & 30,86 \\
\hline 6 - Unidade Campos de Areia & 63,34 & 2,52 \\
\hline 7 - Unidade de Silvicultura & 51,67 & 2,06 \\
\hline 8 - Unidade Urbano & 6,64 & 0,26 \\
\hline 9 - Unidade Cerros de São Francisco & 37,24 & 1,48 \\
\hline 10 - Unidade Colinas do Baixas do Rio Jaguari & 295,36 & 11,77 \\
\hline 11 - Unidade dos Vales Fluviais & 257,62 & 10,27 \\
\hline
\end{tabular}

Tabela 1 - Dados quantitativos de área e percentagem das unidades geoambientais do município de São Francisco de Assis 


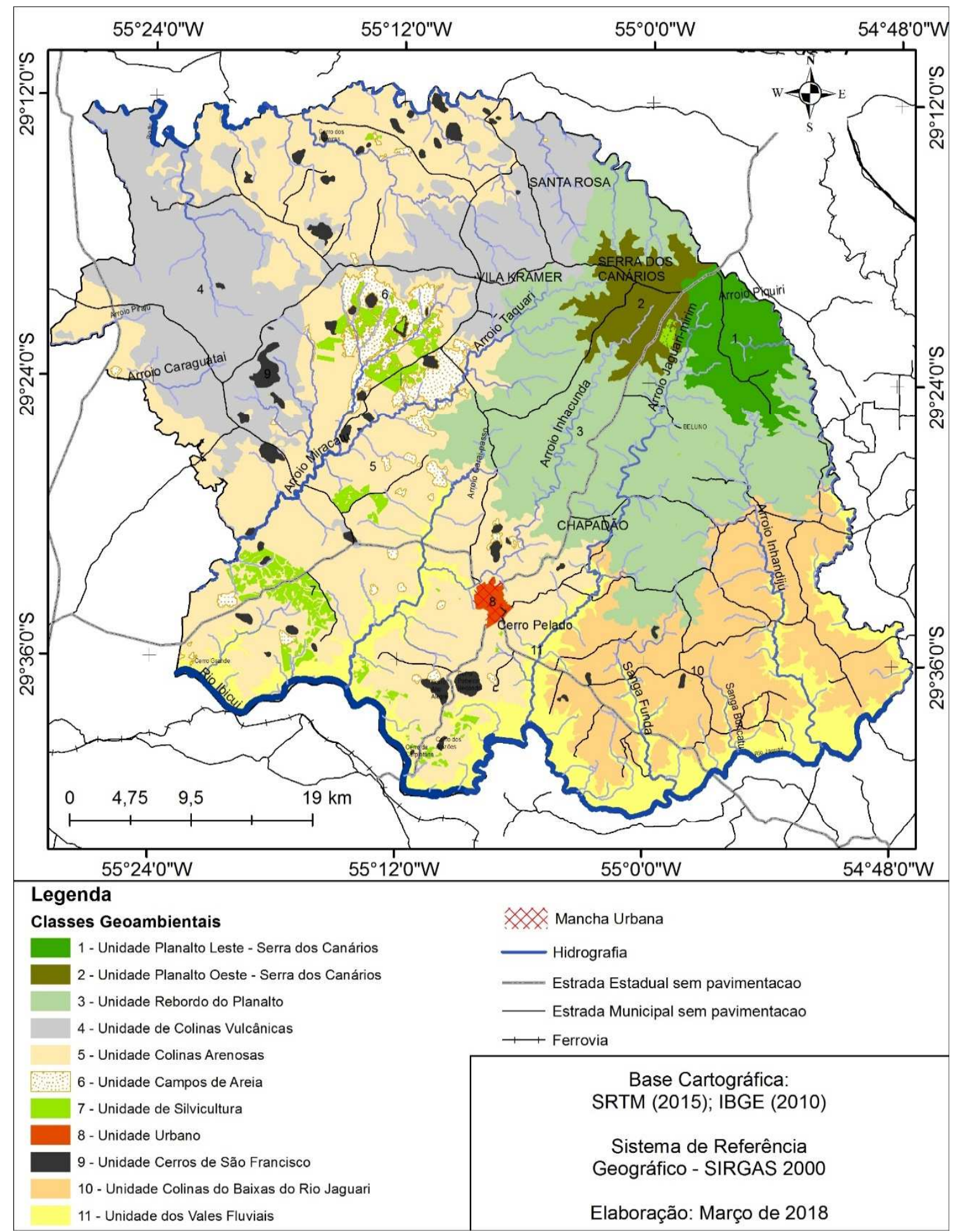

Figura 4 - Zoneamento Geoambiental do município de São Francisco de Assis

\subsection{Unidade Planalto Leste - Serra dos Canários}

Unidade que ocorre nas altitudes superiores a 300 m, pertencente a região geomorfológica do Planalto das Missões (Robaina et al 2010), com drenagens pertencentes à bacia do rio 
Jaguari. O substrato é de rochas vulcânicas em relevo de colinas suaves formando áreas de nascentes, principalmente, dos afluentes do rio Jaguari, como os arroios Jaguari-mirim, Inhandiju e Piquiri. Nessa sub-unidade os solos não são espessos, mas ocorrem solos bem desenvolvidos como Argissolos, provavelmente pela exposição de porções menos resistentes dos derrames. Os solos e o relevo são propícios ao uso agrícola, que predomina na unidade, descaracterizando a vegetação campestre natural. Esta unidade ocorre na porção nordeste do município, ocupando uma área de $75,57 \mathrm{~km}^{2}$, representando 3,01 \% da área total do município.

\subsection{Unidade Planalto Oeste - Serra dos Canários}

Essa unidade apresenta as maiores altitudes do município, se localizando no Planalto, formando nascentes da rede de drenagem ligada diretamente ao rio Ibicuí, como da Inhacundá-Caraí-Passos e Taquari-Miracatu. Os solos são rasos e mal desenvolvidos, como Neossolos litólicos sobre um substrato vulcânico. É comum a exposição destes derrames, na forma de blocos de rochas expostas nos campos, formando solos de pouca profundidade e pedregosos, marcando as fragilidades com relação ao uso desta unidade. Apresenta uma extensa cobertura de campos, formando um denso tapete gramíneo herbáceo, de espécies conhecidas, como o capim-caninha (Andropogon lateralis) e a grama-forquilha (Paspalum notatum) com uso para pecuária, principalmente de bovinos. Esta unidade ocupa uma área de $67,58 \mathrm{~km}^{2}$, o que representa $2,69 \%$ da área total do município, localizada na porção nordeste do município.

\subsection{Unidade Rebordo do Planalto}

A unidade apresenta o relevo mais movimentado do município, marcado pelo recuo da escarpa, caracterizada por elementos de vales e cristas estreitas. Espacialmente ocupa a porção centro nordeste do município. Dois patamares marcam a escarpa: o primeiro constituído por rochas areníticas que formam uma chapada curta e o segundo constituído por rochas vulcânicas, com relevo de morros e morrotes. As rochas variam entre arenitos e vulcânicas com os solos predominantemente pedregosos e mal desenvolvidos. Entretanto, 
na passagem do relevo de colinas para morros e morrotes e no topo das chapadas os solos são rasos, mas bem desenvolvidos em perfil, formando predominantemente argissolos.

Esta unidade localiza-se na porção centro nordeste do município ocupando uma área de $460,59 \mathrm{~km}^{2}$, o que representa $18,36 \%$ da área total do município. O uso e ocupação estão ligados a pequenas propriedades com pequenas lavouras de subsistência e tabaco como principal produto comercial. As áreas são suscetíveis a processos de transporte e movimento de massa, especialmente quando a vegetação da encosta é suprimida.

Nessa unidade, conforme Alves (2008), ocorre de forma extensa e homogênea uma florística diversificada devido às contribuições da Floresta Estacional Decidual. Nestes locais se desenvolvem espécies como aroeira-brava (Lithraea molleoides), aroeira-folha-de-salso (Schinus molle), pau-ferro (Astroniumbalansae), branquilho (Sebastiana commersoniana), camboatá-vermelho (Cupaniavernalis), a pitangueira (Eugenia uniflora), a timbaúva (Enterolobium contortisiliquum), carvalhinho (Casearia silvestris), canela-de-veado (Helietta apiculata), ariticum (Rollinia emarginata, Rollinia salicifolia), mamica-de-cadela (Zanthoxylum rhoifolium), açoita-cavalo (Luehea divaricata), murta (Blepharocalyx salicifolius), gravatá (Bromelia balansae), ipê-roxo (Tabebuia impetiginosa), o araticumfolha-de-salso (Annona neosalicifolia) e o araticum-quaresma (Annona emarginata), chá-debugre (Casearia sylvestris), chal-chal (Allophylus edulis), o tarumã-preto (Vitex megapotamica), o camboatá-branco (Mataybaela eagnoides), a guajuvira (Cordia americana), a canela-preta (Nectandra megapotamica).

\subsection{Unidade de colinas vulcânicas}

A unidade compreende um relevo de colinas que ocorrem em litologias vulcânicas básicas de pouca espessura e arenitos. Os solos variam dependendo da porção do derrame que foi alterado e a resistência do arenito intertrápico. Nas porções de topo de derrame, com material vítreo intersticial os processos de alteração da rocha são mais significativos, gerando solos bem desenvolvidos (Argissolos, Latossolos e Nitossolos), que predominam na parte Central da unidade. Nas demais porções a maior resistência das porções cristalinas do derrame, geram solos rasos mal desenvolvidos, como Neossolos litólicos, que, algumas 
vezes, concentram matéria orgânica no horizonte A. Por serem pouco espessos os derrames presentes nesta unidade, permitem a exposição de pequenas manchas arenosas.

As feições erosivas presentes são ravinas que ocorrem em áreas com exposição dos arenitos. De modo geral, a vegetação arbórea deste sistema se distribui ao longo dos canais, na forma de capões de mata próximos das nascentes. O tipo de uso é a associação pecuária e agricultura. Esta unidade ocupa uma área de 418,75 km², representando 16,69\% da área total do município e estende-se na forma de uma faixa de norte a noroeste do município.

\subsection{Unidade colinas arenosas}

Esta unidade está representada por litologias friáveis da Formação Guará, identificados como arenitos fluviais em relevo de colinas arenosas côncavo-convexas onde predominam os solos espessos, profundos, arenosos e friáveis, com pouco material ligante, predominando Latossolos arenosos, mas ocorrendo, também Neossolos quartzarênicos.

Com relação à vegetação, esse sistema é composto por formações campestres, capões de mato e bosques de eucaliptos. Quanto ao uso, ainda predominam os campos com atividade pecuária, mas existem áreas utilizadas para a agricultura, especialmente lavouras de soja. 0 relevo é propício para atividade agrícola ampla, mas os solos arenosos e com baixo teor de ligantes podem ser usadas com culturas especialmente adaptadas, com extremo cuidado para neutralizar as limitações, principalmente relacionadas com o controle da erosão o manejo da água.

Esta unidade ocupa a maior área no município com $774,13 \mathrm{~km}^{2}$, correspondendo a $30,86 \%$ da área total, estendendo-se por uma longa faixa central norte-sul.

\subsection{Unidade Campos de areia}

Espacialmente a unidade dos areais, localiza-se principalmente no centro do município, associado a unidade de colinas arenosas, ocupando uma área de $63,34 \mathrm{~km}^{2}$, o que representa $2,52 \%$ da área total do município. Os campos de areia marcam uma forma acelerada de erosão dos solos que tem suscitado muita preocupação regional. 
Desenvolvem-se desde a cabeceira de drenagens desmatadas e, principalmente, em encostas convexas junto à base das colinas e arenitos pouco coesos. Forma-se pela ação hidrodinâmica das chuvas em um solo de baixa cobertura vegetal, arenoso e friável. O vento persistente na região, espalha as areias ampliando os campos de areia. A presença de areais no sudoeste do Rio Grande do Sul, segundo dados de diversos autores, é anterior aos primórdios da colonização e sua causa reside na fragilidade do ecossistema.

Em algumas áreas as colinas com campos arenosos e areais são cobertas por uma vegetação nativa muito característica, o butiá-anão. Por sua ocorrência restrita no oeste e sudoeste do Estado, o butiá-anão (Butia lallemantii) representa importante espécie endêmica que caracteriza o Bioma Pampa e atribui um aspecto de savana à vegetação campestre local. Nota-se, todavia, que a ocorrência de alguns polígonos com butiá anão se encontra conectada e sua interrupção está associada ao desenvolvimento de lavouras. As características apresentadas mostram a importância dessa espécie, que por ser típica do ecossistema do Bioma Pampa e estar perdendo espaço pela agricultura e silvicultura, deve ser preservada, para que nos próximos anos não venha a ser extinta do seu ambiente original.

\subsection{Unidade de Silvicultura}

A unidade de silvicultura compreende as plantações de pinus e eucaliptos e foi separada como unidade por representar uma nova proposta de uso da terra na região, diferente do tradicional associado a pecuária e agricultura. Além disso, é importante ressaltar que a presença da vegetação exótica faz com que a ação dos agentes de erosão, vento e água, sejam modificadas e, portanto, alterando a dinâmica superficial da região.

A silvicultura é uma atividade relativamente recente na área de estudo, pois estas plantações comerciais ocorreram nos últimos 10 anos, onde anteriormente se desenvolviam campos com pecuária e agricultura, além de porções com arenização. As extensas áreas para essa atividade incorporam áreas de arenização e se apresenta como principal ponto positivo para os moradores da região. Entretanto, em termos ecológicos, estão sendo destruídas áreas que marcam uma condição paleoclimática regional e que determinam o bioma Pampa, no sul do Brasil. Esta unidade ocupa atualmente $51,67 \mathrm{~km}^{2}$ de área, o que 
representa $2,06 \%$ da área total do município e, espacialmente, distribui-se em diversos fragmentos de áreas espalhados predominantemente pelo centro sul do município, junto às colinas arenosas e a campos de areia.

\subsection{Unidade Urbano}

A cidade, como sede de um município, sempre exerce um papel centralizador e a ela compete oferecer bens e serviços necessários à sua comunidade. A unidade urbano está caracterizada, especificamente pelo perímetro urbano do municípios de São Francisco de Assis, possui uma área de $6,64 \mathrm{~km}^{2}$, o que corresponde a $0,26 \%$ da área total do município, localizada espacialmente na porção centro sul do município. Nessa unidade se encontra a maior concentração populacional da área de estudo, dispondo de serviços e infraestrutura básica, como por exemplo, atendimento à saúde, educação e comércio.

O substrato é formado por rochas areníticas, os solos são arenosos e ocorrem sobre um relevo de colinas. As características das ocupações são definidas por construções baixas e o predomínio de áreas residenciais, mesmo na zona central. Apresenta limitações de infraestrutura e saneamento básico, tendo como principal conflito ambiental a contaminação das águas do arroio Inhacundá-Caraí Passo, devido ao lançamento de esgotos. Outros impactos do sistema urbano nas características naturais e na fisiologia canalizações e a geração de resíduos sólidos.

\subsection{Unidade Cerros de São Francisco}

Esta unidade contempla os morrotes de arenito que ocorrem associados às áreas de litologias fluviais de alta coesão com afloramento de rochas e, em alguns casos, com topo de rochas vulcânicas. Estes morrotes representam uma topografia típica da região, com topos planos e encostas íngremes com vertentes retilíneas e vegetação mais abundante nas escarpas. Nesta unidade os solos são rasos, classificados como Neossolos Litólicos. Processos erosivos são identificados, com muita frequência, na base dos morrotes de arenito, nas zonas de contato com a colina. Encontram-se dispersos por diversos fragmentos 
ao longo do município, principalmente associados às colinas de arenito, ocupando 37,24 $\mathrm{km}^{2}$, o que representa $1,48 \%$ da área total do município.

A vegetação característica dos morrotes de arenito contempla diversas espécies, com destaque para a criúva (Agarista eucalyptoides), o jasmim-catavento (Tabernaemontana catharinensis), o curupi (Sapium haematospermum) e a tuna (Cereus hildmannianus). No topo, a vegetação rasteira adaptou-se às condições locais de baixa umidade e solos rasos.

\subsection{Unidade Colinas do Baixo Jaguari}

Esta unidade se localiza no médio e baixo curso de afluentes do rio Jaguari no município de SFA, desde o arroio Piquiri até ao Jaguari-mirim, na porção SE do município, ocupando uma área de $295,36 \mathrm{~km}^{2}$, o que representa $11,77 \%$ da área total. Formada por um relevo de colinas, o substrato é de arenitos finos, micáceos e solos com espessura de $60 \mathrm{~cm}$ a $1 \mathrm{~m}$ com horizonte textural, sendo classificados como Argissolos.

O uso predominante é de campos com pecuária bovina associado a lavouras de soja/trigo. As condições de relevo e solos favorecem o uso agropecuário, mas são fundamentais técnicas conservacionistas, pois os solos são suscetíveis à erosão.

\subsection{Unidade dos Vales Fluviais}

Nesta unidade ocorrem os depósitos recentes, localizados ao longo dos canais dos rios e arroios, em áreas planas que desenvolvem solos mal drenados chamados de hidromórficos. A principal atividade desenvolvida é o cultivo de arroz, que se associa à disponibilidade hídrica e potencialidade do solo. Grandes áreas alagadas, onde antes havia banhados, foram drenadas para o plantio de arroz.

A maior suscetibilidade desta unidade está associada aos banhados e à mata ciliar, que vem sendo retirada nas últimas décadas, dando lugar ao desenvolvimento da agricultura. A vegetação arbórea mantém-se, dentro das áreas de proteção exigidas pela legislação ambiental, apenas em algumas faixas no canal principal dos Rios Ibicuí e Jaguarí, constituindo uma mata ciliar em forma de faixas, onde as espécies mais características são o Sarandi (Sebastiania schottiana), o coqueiro-gerivá (Syagrus romanzoffiana), o branquilho 
(Sebastiana commersoniana), a pitangueira (Eugenia uniflora), o camboatá-branco (Matayba elaeagnoides) e a aroeira-cinzenta (Schinus lentiscifolius).

\section{Considerações finais}

Os estudos geoambientais visam subsidiar discussões sobre a implementação do planejamento e ordenamento territorial, uma vez que as ocupações nem sempre são precedidas de estudos que considerem as restrições dos recursos naturais, especialmente relacionadas à fragilidade das litologias e dos solos, quando submetidos a determinados usos.

O presente trabalho se propôs definir o zoneamento geoambiental do município de São Francisco de Assis e estabeleceu onze unidades que apresentam um comportamento homogêneo quantos às características de relevo, relacionadas ao substrato geológico e solo e às formas de uso e ocupação.

A grande diversidade presente no município condicionou a definição deste número de unidades, pois especificamente as forma de uso possibilitaram a definição de duas unidades geoambientais, a unidade Urbano, onde se encontra a cidade de São Francisco de Assis, com a maior concentração populacional e maior disponibilidades de serviços e, a unidade Silvicultura que é um atividade que surgiu na última década e proporcionou uma grande mudança na dinâmica de uso do município.

As condições de uso permitiram, ainda, a diferenciação das unidades Planalto Leste - Serra dos Canários e Planalto Oeste - Serra dos Canários que, associados a profundidades dos solos possibilitam maior presença de lavouras no Planalto Leste - Serra dos Canários. As colinas do baixo Jaguari, da mesma forma, tiveram uma importante contribuição do uso associado às lavouras que condicionou a sua definição como unidade Geoambiental.

As condições do substrato litológico e relevo condicionaram a definição principal das demais unidades que, conforme a própria denominação das unidades, se associam principalmente ao Rebordo, Colinas - estas diferenciadas entre os substratos areníticos, predominantemente friáveis e os substratos vulcânicos, os Cerros, a Planície aluvial e os 
campos de areia - estes definidos como unidade Geoambiental por marcarem uma área de acelerada erosão dos solos e despertarem importante preocupação regional.

Deve-se destacar ainda, para a elaboração do presente trabalho, a utilização de geotecnologias, uso do SIG, disponibilidade de imagens de satélite e modelos digitais de elevação, que foram ferramentas cruciais nos procedimentos de definição e análise.

\section{Agradecimento}

A Fundação de Amparo a Pesquisa do Rio Grande do Sul FAPERGS pelo apoio financeiro.

\section{Referências bibliográficas}

ALVES, F. S. Estudos Fitogeográficos na Bacia Hidrográfica do Arroio Lajeado Grande - Oeste do RS. Santa Maria: UFSM, 2008. (Dissertação de Mestrado) $106 \mathrm{f}$.

CARVALHO, J. A. R.; SILVA, A. P.; CAVALEIRO, V. M. M. Cartografia Geotécnica e ambiental em Portugal. In: $5^{\circ}$ Simpósio Brasileiro de Cartografia Geotécnica e Geoambiental. ANAIS. São Carlos, p. 566 - 582, 2004.

CENDRERO, A. Environmental geology of the Santander Bay Area, Norhern Spain. Engineering Geology. v. 1, p. $97-114.1975$.

DE NARDIN, D.; ROBAINA, L. E. S.. Zoneamento geoambiental no Oeste do Rio Grande do Sul: bacia hidrográfica do rio Miracatu. Geografia (Rio Claro. Impresso), v. 34, p. 163-181, 2009.

EMPRESA BRASILEIRA DE PESQUISA AGROPECUÁRIA - EMBRAPA. Centro Nacional de Pesquisa de Solos. Sistema brasileiro de classificação de solos. Brasília, SPI/ CNPS, 1999. 412p

FIORI, A. P. Metodologias de Cartografia Geoambiental. In: 5o Simpósio Brasileiro de Cartografia Geotécnica e Geoambiental. São Carlos: Anais, 2004.

GARÓFALO, D. F. T.; FERREIRA, M. F. M.. Análise geoambiental de bacias hidrográficas situadas em áreas de transição urbano-rural: Uma Aplicação na bacia do Ribeirão do Pântano, Alfenas (MG). Geografia (Rio Claro. Impresso), v. 38, p. 141-156, 2013,

GRECCHI, R. C.; PEJON, O. J. Estudos Geoambientais da Região de Piracicaba (SP), com Auxílio de Imagem desatélite e de Sistema de Informação Geográfica. In: $3^{\circ}$ Simpósio Brasileiro de Cartografia Geotécnica. Florianópolis, Anais, 1998.

INSTITUTO BRASILEIRO DE GEOGRAFIA E ESTATÍSTICA (IBGE). Projeto RADAMBRASIL. Levantamento de recursos naturais (Folha SH.22 Porto Alegre e parte das Folhas SH.21 Uruguaiana e SI.22 Lagoa Mirim). Instituto Brasileiro de Geografia e Estatística, Rio de Janeiro, CD-ROM. 1986.

INSTITUTO BRASILEIRO DE GEOGRAFIA E ESTATÍstICA (IBGE). Produção Agropecuária Municipal - 2014. Disponível em: <http://www.ibge.gov.br/home/estatistica/economia/ppm/2014/>. Acesso em: 7 abr. 2015.

INSTITUTO BRASILEIRO DE GEOGRAFIA E ESTATístICA (IBGE). Malhas Digitais. Municípios 2010. Rio de Janeiro, 2010. Disponível em <http://downloads.ibge.gov.br/downloads_geociencias.htm> Acesso junho de 2015. 
KREITLOW, J. P.; NEVES, S. M. A. S.; NEVES, R. J.; SERAFIM, M. E.. Zoneamento geoambiental da teca no município de Cáceres/Mato Grosso - Brasil. Ra'eGa, v.31, p.53-68, 2014.

KNIERIN, I. S., TRENTIN, R., ROBAINA, L. E. S.. Uso de atributos topográficos para análise e compartimentação do relevo da bacia hidrográfica do Arroio Inhandiju - Oeste do RS - Brasil. Revista Brasileira de Geografia Física. v. 08 n. 04 p. 990-1005, 2015.

LANG. S.; BLASCHKE, T. Análise da paisagem com SIG. São Paulo: Oficina de Texto, 2009.

LAVINA, E. L. The Passa Dois Group. In: ANAIS DO INTERNATIONAL GONDWANA SYMPOSIUM, 7, 1988. São Paulo. São Paulo: Instituto de Geociências, 1988. p. 24-30. 1988.

MENEZES, D. J.; TRENTIN R.; ROBAINA, L. E. S.; SCCOTI, A. A. V.. Compartimentação geomorfológica do município de São Pedro do Sul/RS. Boletim Gaúcho de Geografia, 40: 268-279, maio, 2013.

ROBAINA, L. E. S.; TRENTIN, R.; BAZZAN, T.; RECKZIEGEL, E. W.; VERDUM, R.; DE NARDIN, D. Compartimentação geomorfológica da bacia hidrográfica do Ibicuí, Rio Grande do Sul, Brasil: Proposta de classificação. Revista Brasileira de Geomorfologia, v. 11, n. 2, p. 11-23, 2010.

ROBAINA, L. E. S.; TRENTIN, R.; LAURENT, F.; SCCOTI, A. A. V. Zoneamento morfolitológico da bacia hidrográfica do rio Ibicuí e sua relação com processos superficiais e o uso do solo. Revista Brasileira de Geomorfologia, São Paulo, v.16, n.1, p.63-77, 2015.

SHIMBO, J. Z.; JIMÉNEZ-RUEDA, J. R. Zoneamento geoambiental como subsídio aos projetos de reforma agrária. Estudo de caso: Assentamento Rural Pirituba II. Revista Nera. v.10, n. 10, p. 115-133, 2007.

SOUZA, L. A.; SOBREIRA, F. G.; PRADO FILHO, J.. Cartografia e Diagnóstico Geoambiental Aplicados ao Ordenamento Territorial do Município de Mariana-MG. Revista Brasileira de Cartografia, n. 57. p. 189-203. 2005.

SOUZA, M. L.; GASPARETTO, N. V. L.; NAKASHIMA, P. Diagnóstico geoambiental da bacia do córrego Tenente em Mariluz, Paraná, Brasil. Revista Brasileira de Geociências. v. 38(2). p. 379-391, 2008.

SUERTEgARAY, D. M. A. O Rio Grande do Sul descobre seus “desertos". Ciência \& Ambiente, v. 1, n. 1, p. 3452, 1995.

SUertegarAY, D. M. A.; GUASSEl, L. A.; VerduM, R. Atlas da Arenização: Sudoeste do Rio Grande do Sul. Porto Alegre: Secretaria da Coordenação e Planejamento do Rio Grande do Sul, 2001.

TRENTIN, R.; ROBAINA, L. E. S.. Metodologia para o desenvolvimento de mapeamento geoambiental no oeste do Rio Grande do Sul. In: XI Simpósio Brasileiro de Geografia Física Aplicada, ANAIS 2005, São Paulo, 2005.

TRENTIN, R. Mapeamento geomorfológico e caracterização geoambiental da bacia hidrográfica do rio Itu/Oeste do Rio Grande do Sul/Brasil. Tese de Doutorado. Brasil: Universidade Federal do Paraná - UFPR, 2011. 215p.

TRENTIN, R.; SANTOS, L. J. C.; ROBAINA, L. E. S. Compartimentação geomorfológica da bacia hidrográfica do rio Itu - Oeste do Rio Grande do Sul - Brasil. Sociedade \& Natureza, v. 24, n. 1, p. 127-142, 2012.

TRENTIN, R.; ROBAINA, L. E. S.; SCCOTI, A. A. V. Mapeamento geomorfológico do município de Manoel Viana oeste do Rio Grande do Sul - Brasil. São Paulo, Geociências, v. 32, n.2, p. 333-345, 2013.

TRENTIN, R.; ROBAINA, L. E. S.; SILVEIRA, C. T. Compartimentação geomorfométrica da bacia hidrográfica do rio Itu/RS. Revista Brasileira de Geomorfologia, São Paulo, v.16, n.2, (Abr-Jun) p.219-237, 2015.

VERDUM, R. Approche Géographique des "Deserts" Dans les Communes de São Francisco de Assis et Manuel Viana - Etat du Rio Grande do Sul, Brésil. Tese de Doutorado. França: Université de Toulouse Le Mirail - UFR de Géographie, 1997. 211p.

VERDUM, R., et al. Rio Grande do Sul: paisagens e territórios em transformação. Porto Alegre: Editora da UFRGS, 2004. 319 p.

WILDNER, W; RAMGRAG, G. E.; LOPES R. C.; IGLESIAS, C. M. F. Mapa Geológico do Estado do Rio Grande do Sul. Escala 1:750000. CPRM, Serviço Geológico do Brasil. Porto Alegre, RS. 2006. 